\title{
Influence of Age on Perception of Midwives and Their Performance in Objective Structured Clincial Examination (Osce) in Nigeria
}

\author{
Emon U. Duke ${ }^{1}$, Alberta D Nsemo ${ }^{1}$, Mary M. Ojong-Alasia ${ }^{2}$, Easter C. Osuchukwu ${ }^{1}$, Chigozie A. Nkwonta ${ }^{3}$, Mary O. \\ Mobolaji-Olajide ${ }^{3}$ \\ ${ }^{1}$ Department of nursing Science, University of Calabar, Calabar, Cross River State, Nigeria \\ ${ }^{2}$ Department of Nursing Science, Madonna University, Elele, River State, Nigeria \\ ${ }^{3}$ Department of Nursing, Lagos State University, Ikeja Campus, Lagos, Nigeria \\ Correspondence: Emon U. Duke, Department of Nursing Science, University of Calabar, P.M.B.1115, Calabar, Cross \\ River State, Nigeria
}

Received: June 1, 2015 Accepted: July 1, $2015 \quad$ Online Published: August 7, 2015

doi:10.11114/jets.v3i5.878 URL: http://dx.doi.org/10.11114/jets.v3i5.878

\begin{abstract}
Objective structured clinical examination (OSCE) is a means of assessing clinical competence based on objective testing through direct observation. OSCE, as a method of evaluation, was introduced in 1990 by the Nursing \& Midwifery council of Nigeria (N\&MCN). The aim of this quantitative study is to ascertain if age has any influence on midwives' perception of OSCE and their performance in the examination. Ex-post facto design was adopted for this study. That is because the independent variable was studied in retrospect in order to establish possible relationship with the dependent variables. We were concerned with ascertaining and establishing the status quo and facts at the time of the research and used such facts to analyze data, interpret and extrapolate and also draw inferences. Eight institutions of midwifery education in Akwa Ibom and Cross River states of Nigeria were used for this study. 502 out of 532 midwives who graduated from the institutions between 2004 to 2006 participated in the study. Two validated instruments were used for data collection namely: OSCE stake holder's questionnaire and achievement test on OSCE. The reliability index for perception stood at (r) 0.60 while the index performance stood at (r) 0.66.Data were analyzed using linear regression analysis and one way analysis of variance. Findings show that older midwives had significant higher perception of OSCE than the younger midwives. Conclusion: age has significant influence on midwives' perception of OSCE but perception has no influence on their performance in OSCE.
\end{abstract}

Keywords: perception, midwives' performance, age, OSCE, examination

\section{Introduction:}

\subsection{Introduce the Problem}

Human Perception Consist of disposition to behave in ways that are observably evidenced by performance. It is a fundamental push of a man's activities which manifest as performance. Perception is the pivot on which experiences, attitudes, values, memories and preferences evolve in the process of human development. Attitudes are acquired disposition to act in a particular way (Black 2001, Akubiro and Joshua (2002). A behaviour is directed by a person's perception(Carrulhers, 2003).Objective structured clinical examination (OSCE) is a means of assessing clinical competence based on objective testing through direct observation (Duke, Ojong, Mgbekem, Oyira Osaji \& Diepiri, 2010).It has the singular advantage of giving a wide coverage to the curriculum(Harden, 1988).During oral practical examination the examiner is not expected to talk to the candidate; the examinee reads the questions and directs her answers to the evaluator as she carries out the procedure or discusses with the clients. The examiner observes and evaluates the candidate using a checklist (Jain, Delisa \& Campanolo, 2001).

These activities are at variance with the traditional oral/practical examination which is conducted in the open wards; where both the examiner and the examinee interact and discuss by way of oral questions and answers with practical demonstration where applicable. The traditional oral/practical examination is still used to evaluate students of other programs under the umbrella of the Nursing \&Midwifery Council of Nigeria; such as basic general nursing. The clockwise movement fromone station to the other as well as and the numerous sounding of bell in OSCE add to the 
extraordinary nature of the examination. A group of students held a discussion about OSCE; they referred to it as "barbaric, a terrifying experience". Based on this premise the researchers seek to find out if midwives' age and their perception of OSCE affect their performance in the examination.

\subsubsection{Purpose of the Study}

The purpose of this study was to explore the influence of age on midwives' perception of OSCE and their performance in the examination. The study specifically sought to:

Determine if age has any influence on midwives' perception of OSCE and their performance in the examination.

(ii) To ascertain if age and perception jointly influence performance in OSCE.

A previous study exist that surveyed the influence of marital status on attitude of midwives towards OSCE and their performance in the examination; but no study has looked at the influence of age on perception of midwives and their performance in OSCE. This is the first of its kind.

\subsubsection{Research Questions}

How does midwives' perception of OSCE affect their performance in the examination when age is considered?

Does there exists a joint influence of midwives' perception of OSCE and age on their performance

in the examination?

\subsection{Statement of Problem}

Research studies in Objective Structured Clinical Examination (OSCE) have focused on clinical competences such as infection control and hand washing. Very recently there was another study on influence of marital status on attitude of midwives towards OSCE and their performance in the examination. No research work has looked at possible influence of age on perception and performance when OSCE is considered. Thus the crunch to find out if age has any influence on midwives' perception of OSCE and their performance in the examination.

\subsection{Literature Review}

Literature was reviewed under the following headings:

*Perception and academic performance

* Age and perception

* Age and academic performance

* Student's perception of OSCE and academic performance

\subsubsection{Perception and Academic Performance}

The process of disposition of information whether activated or not is called perception. It is regarded as being subsequent to intake of perceptual information which in turn gives rise to performance at various levels (George, 2004). Perception is influenced by motive (Millikan, 2003).

In a previous study to ascertain the effect of perception on academic performance, Alexander and Judy (2002) found that perception is an individual predictor of performance. Rindermann \& Neubauer (2001) opined that perception (personality) is a good predictor of academic performance. Blicke (2005) states that in assessing perception and academic performance, openness to experience is associated with academic performance. Blicke emphasized that this association has often been interpreted in terms of the fact that personality factors seem to be correlated with intelligence.

Johnson (2000) and Saucier (1994), noted that openness to experience, particularly its "Aesthetics" and "ideas" scales, is related to lexical intellect. Furthermore, McCrae and Coasta (2003) reported a significant correlation between openness to experience factor and academic performance. McCrae et al. (2003) further argued that personality traits such as extroversion neurotism are theoretically and empirically associated with academic achievement; mainly as a consequence of similarities and mental speed.

\subsubsection{Age and Perception}

Marcus (2002) carried out a study to ascertain how age affects students' perception. Six hundred and sixty nine (669) students; age ranging from 18-84; from University of Chicago and Florida formed the sample size. The study lasted three (3) years. The study also sought to establish the relationship between age and perceived needs and goals. Findings showed as follows: i) age is correlated positively with perception, ii)as the age of respondents increased their status also 
increased, with corresponding decrease in their practical needs, The level of their goals however increased. Perception is an individual predictor of performance (Alexander and Juddy, 2002).

A correlated study examined the relationship between students' intrinsic value, test anxiety and use of learning strategies and their perception; by Pintrich De Groot and Arbor (2003). 837 graders from 5 Science and 7 English classes formed the sample size. Their ages ranged from 12-18 years. Findings showed that age was closely related to intrinsic value, test anxiety, and use of learning strategies which in turn relate positively with perception (Resnick, 2003, Rogers, 2001). Perception (personality $\}$ is a good predictor of academic performance (Rindermann and Neubauer, 2001).

Malone (2003) in a previous study explored the relationship between students' age and perception. Two hundred and five (205) students from University of Michigan formed the sample size. Their ages ranged from 18-65years. The results showed that the younger respondents did not relate positively with regards to perception while the older respondents did. The findings also showed that age has no influence on perception.

Ames and Archer (2004) carried out a study to determine the relationship between age and students perception. Results showed that perceived competencies and affective reactions such as anger, pride, guilt and fore knowledge of situation showed positive relationship. The finding also revealed that motivational components such as students' reason for enrolling in the programme related favourably to perception. Paris and Oka (2003) opined that age regardless of the group, has a positive influence on perception in so long as the person has fore knowledge of the situation.

\subsubsection{Age and Academic Performance}

Amoo and Rothman (2004) carried out a study to determine influence of age on academic performance among two hundred and sixty (260) junior secondary school students in three local government areas in Lagos state. The findings show a significant positive influence. Four years later the investigators repeated the study among the same group of students. Findings showed a non- significant influence. The investigators observed that as age increase performance decrease.

Barling, Zacharatos and Hepburn (2007) sought to find out if age has influence on academic performance. One hundred and twenty (120) undergraduates formed the sample for the study. Results showed age to be a non-predictor of performance. Age has no influence on performance (Kronsnick and Alwin, 2003). It is attitude that influences academic performance (Duke, 2010). Eccles, (2005) sought to determine if age has any relationship with academic achievement. Two hundred and nineteen (219) undergraduates participated in the study. Participants' ages ranged from 18-45years. The result of the study showed that age has no significant relationship with academic achievement. Eccles emphasized that, capable students, who block out distractors and maintain their cognitive engagement in a given task will definitely achieve. According to Corno and Rohr-kemper (2004) students who persist at difficult tasks; maintaining their cognitive engagement in the task; will perform better academically.

\subsubsection{Students' Perception of OSCE and Academic Performance}

In a previous study to ascertain if students' motivation negatively included by an assessment methodology with low face validity resulted in poor performance Cohen, Rothman, Bulan and Rose (1996) used 30 students, fourteen (14) females and sixteen (16) males. Findings showed that 24(80\%) respondents felt OSCE was fair; of the six (6) who felt OSCE was unfair ,three (3) indicated time shortage of time. Two (2) students blamed the possibility of poor performance on the day. One (1) felt OSCE included inappropriate materials. The investigation showed that four (4) students failed on grounds of poor performance. OSCEs test a wide range of skills, thus reducing the "sampling errors"(Duke et al., 2010). According to Harden (1988) the real power of OSCE lies in the ability of those responsible for teaching OSCE and the examiners to examine their candidates with imagination and fore thought. OSCE stresses on what student can do rather than what students know (Singer, Cohen, Robb and Rothman 2001).

Sloan, Donnelly, Schartz, Felt, Blue and Strodel (1996) explored students' perception of examination attributes in the University of West Indies. 113 undergraduates participated in the study. Findings showed a significant positive acceptance of OSCE. The result also showed that OSCE was perceived favourably. The findings however revealed that OSCE is a strong anxiety producing experience. Furthermore, the finding showed that time allocated for expected tasks was inadequate. Mottram (2001) assessed how students perceived OSCE. A fourth year student viewed OSCE as the most barbaric examination ever invented. Furthermore the researcher reported that another student perceived that, in an OSCE; the last minute cramming ends up abruptly, as a student hears the first bell she instantly forgets anything she has learnt in the past few weeks. OSCE is a "terrifying experience", but like anything else a few hints and tips can make all the difference (Tomlins, 2006, Moody and Dyer, 2005, Lazarus and Kent, 2005, Harts, Wiker and pickerring, 2001). 


\subsubsection{Research Hypotheses}

$\mathrm{H}_{01 \text { : }}$ There is no significant influence of midwives' age on their perception of OSCE and their performance in the examination.

Independent variable: Midwives' age.

Dependent variable: Midwives' perception of OSCE and performance in OSCE.

Statistical treatment: Analysis of variance

$\mathrm{H}_{02}$ : There is no significant joint influence of age and perception of OSCE on performance in the examination.

Independent variables: Midwives' age and perception of OSCE.

Dependent variable: Performance in OSCE. Statistical treatment: linear regression model.

\section{Research Methods}

\subsection{Research Design}

Ex-post facto design was adopted to study the independent variable retrospectively, in order to establish possible relationship with the dependent variable, in 8 institutions of midwifery education in Akwa Ibom and Cross River states of Nigeria. The design of ex-post facto was chosen because direct control of the variables was not possible, neither was experimental manipulation nor random assignment used by the investigators. In this study the independent variables had already occurred. The researchers merely began with observation of the dependent variables. We were concern with ascertaining and establishing the status quo and facts at the time of the research and used such facts to analyze data, interpret and extrapolate as well as draw inferences.

\subsection{Participants}

502 midwives who graduated from eight (8) institutions of midwifery education between 2004 and 2006 from Akwa Ibom and Cross River states participated in the study. A total of 532 midwives actually graduated from the said institutions within the period of study but 502 midwives volunteered to participate in the study. The break-down is as follows:

Table1. Distribution of the population study

\begin{tabular}{ccccc}
\hline Years & State & Month & Number of & Number \\
\hline & & & $\begin{array}{c}\text { Students' enrolment per } \\
\text { State per year }\end{array}$ & selected \\
2004 & AKS & March & 59 & 59 \\
2004 & AKS & September & 20 & 20 \\
2004 & CRS & March & 48 & 48 \\
2004 & CRS & September & 8 & 8 \\
2005 & AKS & March & 111 & 111 \\
2005 & AKS & September & 19 & 19 \\
2005 & CRS & March & 45 & 45 \\
2005 & CRS & September & 13 & 13 \\
2006 & AKS & March & 104 & 104 \\
2006 & AKS & September & 19 & 19 \\
2006 & CRS & March & 67 & 67 \\
2006 & CRS & September & 19 & 19 \\
TOTAL & & & 532 & 532 \\
\hline
\end{tabular}

Source: Nursing Department, Ministry of Health, Calabar, CRS.

KEY.

AKS $=$ Akwa Ibom State.

$\mathrm{CRS}=$ Cross River State

\subsection{Sample and Sampling Technique}

Purposive sampling method was used to select the sample for this study. This technique is used for convenience when other techniques cannot be applied. A total of 502 midwives who were willing to participate in the research were engaged for the study. Five hundred and two (502) midwives formed the sample size. 


\section{Result}

Table 2. One way analysis of variance of influence of age on midwives' perception of OSCE and their performance in OSCE

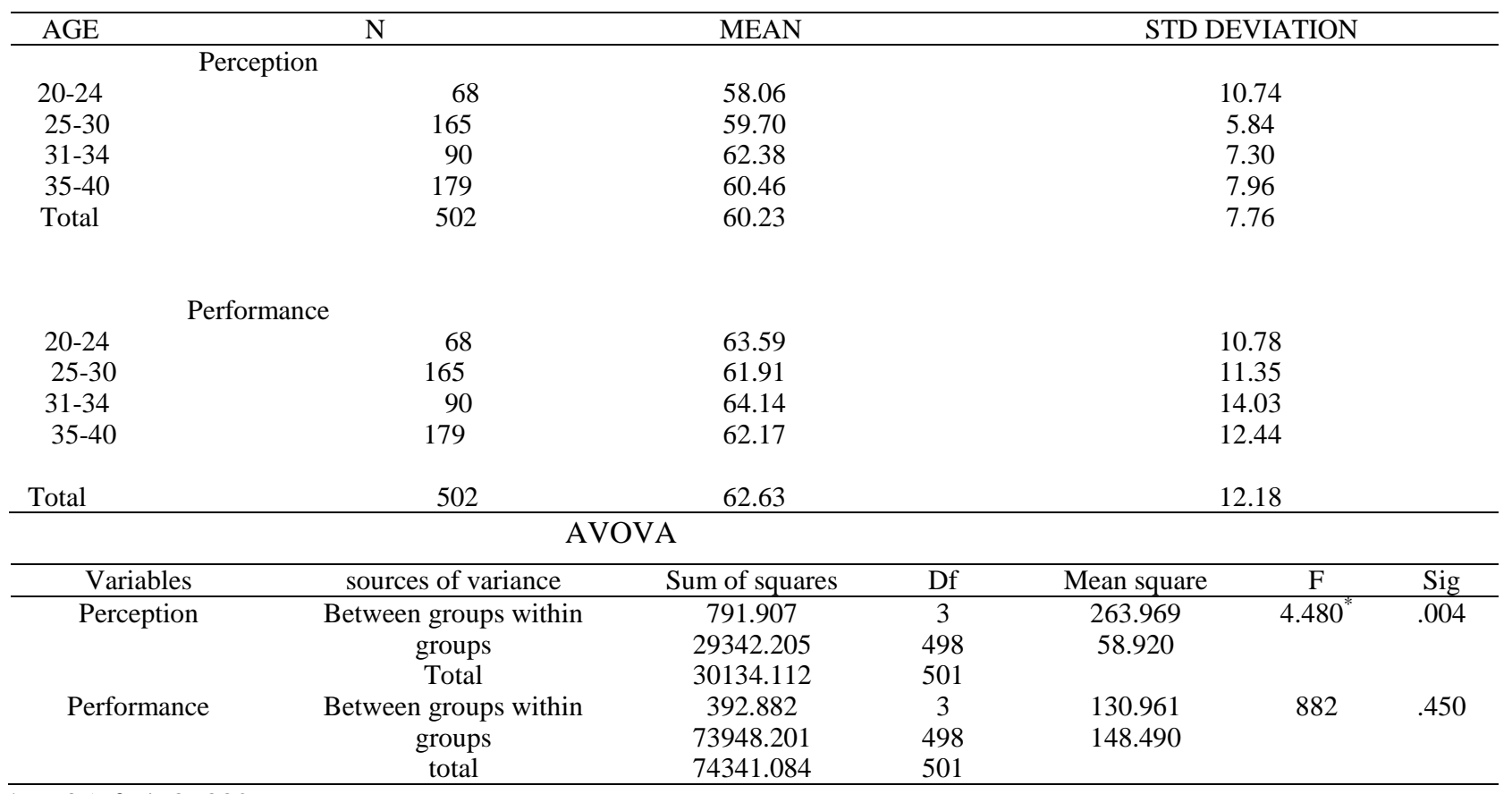

*P<.05; $\mathrm{f}_{3} 498=882$

This result shows that the mean perception, and performance of midwives within the age rangeof 31-34yrs was higher $\left(x_{p}=62.38, \times a=29.48\right)$ and $\left(x_{p e r f}=64.14\right)$,followed by midwives within the age range of $35-40\left(x_{p}=60.46\right)$ and $\left(x_{\text {perf }}=62.17\right.$ ) however the mean performance of midwives within age range 20-24yrs showed a higher mean score for performance $\left(x_{\text {perf }}=63.59\right)$ than midwives within the age range of $25-30 y r s\left(x_{\text {perf }}=61.91\right)$. When these means were compared using one way analysis of variance the result showed significant influence of age on perception of $\operatorname{OSCE}\left(\mathrm{F}_{3}, 498=4.48, \mathrm{P}<\mathrm{O} 5\right)$; but no significant influence of age on performance of midwives in OSCE $\left(\mathrm{F}_{3}, 498=882\right.$ $\mathrm{p}>0.05$ ).The null hypothesis is rejected in case of perception of OSCE but retained for performance in OSCE .This result shows that age has significant influence on midwives perception of OSCE but does not have any influence on midwives performance in OSCE.

Table 3. Fishers LSD multiple comparison test of influence of age on midwives perception of OSCE

\begin{tabular}{ccccc}
\hline Age & $20-20 \mathrm{yrs}$ & $25-30 \mathrm{yrs}$ & $31-34 \mathrm{yrs}$ & $35-40 \mathrm{yrs}$ \\
\hline & $\mathrm{N}=68$ & $\mathrm{~N} 165$ & $\mathrm{~N} 90$ & $\mathrm{~N} 179$ \\
$20-24 \mathrm{yrs}$ & 58.06 & 1.646 & 4.32 & -2.40 \\
$25-30 \mathrm{yrs}$ & 1.48 & 59.70 & 2.68 & -.7 .6 \\
$31-34 \mathrm{yrs}$ & 3.51 & 2.68 & 62.38 & 1.96 \\
$35-40 \mathrm{yrs}$ & 2.20 & 0.92 & 1.94 & 60.46 \\
& & $\mathrm{M} W=58.920$ & -1.23 & -0.93 \\
$20-24 \mathrm{yrs}$ & 28.2 & $-.58 \mathrm{~b}$ & -1.83 & -1.53 \\
$25-30 \mathrm{yrs}$ & 0.82 & 27.67 & 29.49 & -.30 \\
$31-34 \mathrm{yrs}$ & 1.56 & 2,84 & -0.4 & 29.18 \\
$35-40 \mathrm{yrs}$ & 1.33 & 2.87 & & \\
& & MSW=24.170 & \\
\hline
\end{tabular}

*Significant at 0.5, (a) Group means are along diagonal, (b) Difference between group means are above the diagonal

Fishers LSD + values are below the diagonal

Multiple comparison test analysis using fishers least square difference (table 3 ) to locate the source of difference shows that midwives within the age bracket 31-34 had significant higher mean perception of OSCE than midwives within the age bracket of 20-24yrs $(\mathrm{t}=3.51 ; \mathrm{p}<05$ and between $25-30 \mathrm{yrs}(\mathrm{t}-2.68 ; \mathrm{p}<05)$.In the same vein midwives within the age bracket 35-40yrs had significant higher mean perception of OSCE than midwives within the age bracket20-24(t=2.20; $\mathrm{p}<05$. This finding means that older midwives had significant higher perception of OSCE than younger midwives. 
If there is a significant joint influence of midwives' perception and age on their performance in OSCE; to test this hypothesis the linear regression model was used to predict midwives' performance under the influence of perception and age as criterion variables.

Table 4. Inter correlation amongst the variables of the study $(\mathrm{N}=502)$

\begin{tabular}{ccccc}
\hline Variable status & Performance & Perception & Attitude & Age \\
\hline Performance & 1.0 & $.18^{* *}$ & $.15^{* *}$ & .01 \\
Perception & & 1.0 & $.23^{* *}$ & $10^{*}$ \\
Age & & & & 1.00 \\
\hline
\end{tabular}

$* \mathrm{P}<.05 ; \mathrm{R}=0.23, \mathrm{R}^{2}=0.051$

The result shows correlation among variables while table5 is the regression model. The correlation coefficient is significant except age on midwives' performance with $\mathrm{R}^{2}=0.051$. This means that $5.1 \%$ of variability of midwives' performance in OSCE is jointly accounted for by predictor variables of perception and age. The information in table 5ashows that perception and age are significant joint predictors of midwives performance in OSCE $(\mathrm{F}=6.74 \mathrm{P}<001)$.Hence the null hypothesis was rejected at 0.5 level of significance.

Table 4. 5a. Regression analysis of prediction of midwives' performance in OSCE using perception of OSCE and age of midwives as criteria

\begin{tabular}{|c|c|c|c|c|c|}
\hline Sources of Variable & $\begin{array}{c}\text { Sum of } \\
\text { Square(SS) }\end{array}$ & $\begin{array}{c}\text { Degree Of } \\
\text { Freedom(DF) }\end{array}$ & $\begin{array}{c}\text { Mean Square } \\
(\mathrm{MS})\end{array}$ & $\mathrm{F}$ & Sing of $F$ \\
\hline Regression & 3825.580 & 4 & 956.39 & 6.74 & $.000^{\mathrm{a}}$ \\
\hline Residual & 70515.59 & 497 & 141.88 & & \\
\hline Total & 7434.08 & 501 & & & \\
\hline Table 4.5b. & \multicolumn{2}{|c|}{ Un standardized coefficient } & \multicolumn{2}{|c|}{ standardized coefficient } & \\
\hline Variable & $\begin{array}{c}\text { Standard } \\
\text { error }\end{array}$ & Beta $\quad \beta$ & $\mathrm{t}$ & Sign $\mathrm{t}$ & \\
\hline Constant 42.31 & 4.86 & 8.71 & .000 & & \\
\hline Perception .26 & .07 & .16 & 3.59 & .000 & \\
\hline Attitude .28 & .11 & .16 & 2.54 & 0.1 & \\
\hline Age -12 & .55 & -.01 & -.21 & .84 & \\
\hline
\end{tabular}

$* \mathrm{P}<.05 ; \mathrm{R}=.23, \mathrm{R}^{2}=0.57 * \mathrm{P}^{<} .05$,

The regression model also shows the contribution of each of the variables in the prediction of midwives' performance in OSCE .The result on table 5bshows perception as the most significant predictor $(\beta=16, t=3.59)$, except age $(\beta=01$, $t=21)$ with a coefficient of determination $\left(\mathrm{R}^{2}=0.051\right)$ meaning that any variation in midwives' performance in OSCE is accounted for by $5.1 \%$ variation in a combination of predictor variables. The result on table 4 shows that perception is an individual significant predictor of performance in OSCE, since the sign associated with the regression weight $(ß)$ indicates the direction of prediction ,it follows that the prediction of performance in OSCE by perception is positive while that of age is in the reverse direction. This means that the higher the perception the higher the midwives' performance in OSCE. The negative direction as regards age means that as age increases performance decreases. However, the result has shown that perception of OSCE and age are significant joint predictors of midwives' performance in OSCE.

\section{Discussion}

Influence of midwives' age on perception of OSCE and their performance in the examination.

$\mathrm{H}_{01}$ sought to find out if midwives' age significantly influences their perception of OSCE and their performance in the examination. The findings of this study show a significant influence of age on perception of OSCE, but the result shows a non-significant influence of age on midwives' performance based on OSCE. These findings agree with that of Marcus (2002) who found age to be positively correlated with perception. The finding of this study is also in line with that of Pintrich, De Groot and Abor (2003) who viewed that age is closely related with intrinsic value, test anxiety and use of learning strategies which in turn are positively related to perception. Again the findings are in consonance with the views of Ames and Archer (2004) which state that motivational components such as students' reason for enrolling in the programme related favourably to perception. As regards to age and academic performance the finding of this study is at variance with that of Amoo and Rothman (2004) which found a significant positive influence of age on academic performance. But the findings of this study agree with the views of Amoo and Rothman who four years after a previous research study found a non positive influence with the same group. The possible explanation could be that as age increases individuals get more entangled with other rolls which may interfere with their achievements academically. Further analysis using fisher's least square difference showed that, older midwives had significant higher perception of OSCE than younger midwives. This finding is similar to the finding of Malone (2003) which showed that younger respondents did not relate positively with perception but older respondents related positively with perception. Age more 
than any other factor affects perception, he concluded. Furthermore the findings of this study disagree with Paris and Oka (2003) who opined that age regardless of the group, has a positive influence on perception in so long as the person has fore knowledge of the situation.

These findings are at variance with the findings of Mosha (1999); Who found that performance in general knowledge and mathematics depended on the age of the pupils. The findings of this study agree with that of Barling, Zacharated and Hepburn (2007) who opined that age was not a predictor of academic performance. Age has no influence on academic performance (Kronsnick and Alwin (2003), Eccles (2005) Corno and Rohr-kemper (2004). These findings imply that if a student determines to achieve, irrespective of age the student will achieve but age can affect one's belief, values and even behavior towards a given situation.

Perception of OSCE and age as joint predictors of midwives' performance in OSCE

This hypothesis sought to find out if midwives' perception and age are joint predictors of their performance in OSCE. The results show a significant relationship between midwives' perception of OSCE, age and their performance in OSCE. Further analysis showed that as midwives' perception of OSCE increases, their performance in OSCE increase but as age increases performance decreases. The finding support the view of Carrulhers (2003) who opined that often times perceptions are the basis of human actions and behaviours. The finding is in consonance with the views Molner (2003) which stated that action or behavior is based on the decision taken on the basis of one's perception. The finding of this study agrees with that of Barling, Zacharatos and Hepburn (2007) who opined that age is not a predictor of academic performance.

This finding imply that since attitudes are products of perception, if a person's feelings about an object are positive his behavior towards that object will be positive. Thus, if midwives' perception of OSCE is positive this will influence performance in OSCE positively. In other words perception being a value is more stable than behaviours and intensions. Perception preempts interests to manifest as determinations and disposition. Again the findings of this present study imply that learners who persist at difficult tasks, maintain their cognitive engagement in the task, and so achievement and this is the case in OSCE ( Corno and Rohrkemper, 2004). Capable students who block out distractors such as noisy class mates maintain their cognitive engagement in a given task (Eccles, 2005).

\section{Conclusion}

It is concluded that age has no influence on midwives' performance in OSCE. In other words if a student is determined to achieve she will achieve irrespective of her age. But age can affect a person's belief, values ( perception) and even behaviour towards a given situation.

\section{Acknowledgement}

We are grateful to all the midwives who participated in this study. Our gratitude extends to mr Duke, Solomon for his contribution to this work. We return all glory to God Almighty for His grace upon us all through the period this research study was conducted.

\section{References}

Akubiro, I. M., \& Joshua, M. T. (2002). Self-concept attitude and achievement of secondary Students in science in southern Cross River State. Nigeria. Online the African Symposium 4(1). http: //www2.ncsu.edu/nesu/aern/seksien\&htm! 30-6-2007

Alexander, P., \& J. (2002). The effect of perception on academic performance. Journal of Research and personality, 23, $119-228$.

Ames, C., \& Archer, J. (2004). Age and perception of community Midwifery, paper presented in a Workshop. Unpublished.

Amoo, S. A., \& R0thman, M. A. (2004). Secondary School Student's attitude of learning Mathematics In Akale, M. A. $\mathrm{J}(\mathrm{Ed})$ in the world of information technology: implication for mathematics teachers and teacher preparation. Proceedings of the $45^{\text {th }}$ Annual conference of STAN 175-182

Austine, Z., O'Byrne, C., Pugsley, J., \& Munoz, L. O. (2003). Instructional Design and Assessment, Developing and validating processes for an objective structured clinical examination (OSCE) for entry to practice certification in pharmacy. American journal of Pharmaceutical Education, 67(3), http://dx.doi.org/10.5688/aj670376

Barling, J., Zacharatus, A., \& Hepburn, C. G. (2007). Influence of Age on adolescents' academic performance. American Psychological Association.

Black, N. (2001). Behaviorism Revisited. Behavioral and Brain Science, 24, 977-978. http://dx.doi.org/10.1017/S0140525X01270113 
Blickle, G., (2005). Personality traits, learning strategies and Academic Performance, European Journal of personality 10, 337-352. http://dx.doi.org/10.1002/(SICI)1099-0984(199612)10:5<337::AID-PER258>3.0.CO;2-7

Carrulhers, P. (2003). Moderating Massive Modularity in AO'Hear (Ed). Mind and Persons. Cambridge: Cambridge University press.

Cohen, R., Rothman, N., Bilan, S., \& Ross, J. (1996). Analysis of psychometric Properties of eight administrations of an objective structured clinical examination used to assess international medical graduates. Academic medicine 71 , 522-524. http://dx.doi.org/10.1097/00001888-199601000-00032

Corno, I., \& Rohr-Kemper, I. (2004). The role of age in cognitive engagement and academic performance. Research on motivation, 2.362-368.

Cuttance, P. F. (1980). Affective factors in the mediation of background effects on cognitive performance. Studies in Educational evaluation, 6(1), 65-72. http://dx.doi.org/10.1016/0191-491X(80)90010-3

Duke, E. U. (2010). Graduate Midwives' Perception And Attitude Towards Objective Structured Clinical Examination (OSCE) And Their Performance In The Examination In Cross River And AkwaIbom States. Ngeria. Unpublished $\mathrm{PhD}$ Dissertation, University of Calabar.

Duke, E. U., Ojong, I. N., Mgbekem, M. A., Oyira, E. J., Osaji, T. A., \& Diepiri, B. B. (2010). Midwives' Perception of Objective Structured Clinical Examination(OSCE)and their performance in OSCE in Akwalbom and Cross River States. International professional Nursing Journal,8(2), 7-12.

Eccles, J. (2005).Expectances, values and academic behaviours. In J. T. Spence(Ed) Achievements and Achievement motives. San Francisco: Freeman, 74-146.

George, A. (2004). Linguistics practice and its discontents: Quineand Davidson on the sourceof sense, Philosophers Imprint., 4(1). http://www.philosphersimprint.org/004001.

Hardan, R. M. (1988). Eight yearsexperience with a structures clinical examination. Medical education, 19(3),200-204.

Harts, K. E., Wiker, C., \& Pickering, J. A. (2001). A survey of medical students' view about the purpose and four ness of OSCE. Medical Education, 36(9), 879-886.

Jain, G., Delisa, M. N., \& Campanolo. (2001) . The validity and reliability of an OSCE in dentistry. European journal of dental education, 3 117-125.

Johnson, J. A., (2000). Classification of five factors with help of Ass models. European Journal of personality, 8, 34-38.

Krosnick, J. A. \& Alwin, D. F. (2003). Aging and Susceptibility to attitude change. Journal of personality and Social psychology, 57,416-425. http://dx.doi.org/10.1037/0022-3514.57.3.416

Lazarus, D. I., \& Kent, R. (2005). Techniques for measuring clinical competence. Using objective structured clinical examination. Medical Education, 38, 199-203.

Malone, T. W. (2003).Age and perception of intrinsically motivating instructions. Cognitive science, 5, 333-368. http://dx.doi.org/10.1207/s15516709 $\operatorname{cog} 0504 \_2$

Marcus, E. E. (1993).Effect of age and perception of the utility of participation in Education. paper presented in a seminar. Unpublished material.

McCrea, R., \& Costa, A. (2003). Openness to experience as a basic dimension of personality. Imagination, cognition and personality 13, 39-55. http://dx.doi.org/10.2190/H8H6-QYKR-KEU8-GAQ0

Millikan, R. (2003). Varieties of meaning, 2002 NICOD lectures. Cambridge : Macmillan press.

Moody, K. G., \& Dyer, S. (2005). Application of objective structured clinical evaluation of pharmacist's continuing competence. American Journal of Pharmaceutical education, 61, 117-126.

Mosha, H. J. (1999).A reassessment of the indicators of primary education qualities in developing countries: Emerging evidence from Tanzania. International review of education, 34(1), 17-55. http://dx.doi.org/10.1007/BF00601916

Mottram, V. (2003). Students perception and the usefulness of objective structured clinical examination (OSCE). India pharmacol, 26, 188-189.

Nunlly, J. (1967). Psychometric Theory. New York: McGraw-hill.

Pintrich, P. R., Gegroot, E., \& Arbor, A. (1990). Motivation and self-regulated learning components of classroom academic performance. American psychological association,82(1),33-40.

Pintrich,P. R., Degroot, E., \& Arbor, A. (2003). Effect of motivation and learning strategies on perception. American 
Psychological Association, 8(2), 34-41.

Prawatt, R. S. (1983). Attitude differences between students in general mathematics and algebra. Journal of Educational research, 76(4), 215-220.

Resnick, J. L. (2003). Test Anxiety (Online Serial). http://www.counsel.ufl.ed/sel-help/testanxiety.asp.Retrived 2010.

Rindermann, M., \&Neubauer. (2001). Academic work review. Educational Research, 53, 159-200.

Rogers, M. (2001). Test Wiseness (Online serial). http://www.compusmart.ab.ca/pcottett/edae485/section5wisepage.htm. 7-5-2-10.

Saucier, G. (1994). Mini-markers: A brief version of Goldberg \& unipolar Big-five markers, Journal of personality assessment 63, 506-516. http://dx.doi.org/10.1207/s15327752jpa6303_8

Schoohein-Klein, M., Walmsley, A. D., Habets , L., Vander, V. U., \& Monogue. (2003). Attitude of undergraduate student towards objective structured practical examination pharmacology. Public medicine 16(1), 942-45.

Singer, P. A., Cohen, R., Robb, A., \& Rothman, A. (2001). The ethics of objective structured clinical examination (OSCE). Journal of General Internal Medicine, 8, 23-28. http://dx.doi.org/10.1007/BF02600289

Sloan, D. A., Donnelly, M. B., Schwartz, R, W., Felts, J. L., Blue, A. V., \& Strodel, W. E (1996). The use of objective evaluation and instructions in graduate examinations. Medical Education. J. Surg. Res.,63(1), 225. http://dx.doi.org/10.1006/jsre.1996.0252

Tomlins, P. (2006). Students' attitude towards objective structured clinical Examination (OSCE). European Journal of clinical pharmacology, 51(1), 1-5.

This work is licensed under a Creative Commons Attribution 3.0 License. 